\title{
ANÁLISE DA SEGREGAÇÃO SOCIOESPACIAL A PARTIR DA TEORIA DA SINTAXE ESPACIAL: Um estudo sobre a cidade de São Carlos -SP
}

\author{
Barbara Vallilo Siqueira \\ UFSC - Universidade Federal de Santa Catarina \\ babisv.arq@hotmail.com

\section{Gabriela Willemann Siviero Maximo} \\ UFSC - Universidade Federal de Santa Catarina \\ gabrielaarquiteta@gmail.com \\ Orientador da Investigação: Renato Tibiriça de Saboya \\ rtsaboya@gmail.com
}

\section{RESUMO}

O trabalho aborda o estudo sintático da segregação socioespacial em São Carlos, cidade brasileira de porte médio situada no centro oeste do estado de São Paulo, que apresentou nas últimas décadas um crescimento populacional associado à expansão da dinâmica industrial como parte importante da redistribuição locacional da atividade industrial no país. Desta forma, este artigo tem como objetivo identificar a lógica de produção do espaço urbano existente em São Carlos e, quais são as características demográficas presentes na atual dinâmica de expansão industrial. A metodologia utilizada para a realização da presente pesquisa está balizada em leitura teórica, levantamento de dados e sistematização das informações para análise territorial a partir dos resultados obtidos pela Sintaxe Espacial. A partir dos resultados encontrados pode-se perceber a existência da segregação socioespacial na cidade, analisadas a partir do ponto de vista configuracional, e que esta segregação tende a ocorrer em decorrência, também, pela influência da atividade econômica industrial.

Palavras-chave: segragação socioespcial; sintaxe espacial, cidades médias

\begin{abstract}
The study deals with the syntactic study of socio-spatial segregation in São Carlos, a medium-sized Brazilian city located in the midwest of the state of São Paulo, which in recent decades has shown a population growth associated with the expansion of industrial dynamics as an important part of the locational redistribution of the activity Industry in the country. This article aims to identify the logic of the production of the existing urban space in São Carlos and, what are the characteristics present, in the current dynamics of industrial expansion. The methodology used to carry out the present research is based on: Theoretical reading; Data collection and systematization of information and Territorial analysis from the results obtained by Spatial Syntax. From the results found, one can perceive the existence of socio-spatial segregation in the city, analyzed from a configurational point of view, and that this segregation tends to occur due to the influence of industrial economic activity
\end{abstract}

Keywords: socio-spatial segregation; Spatial Syntax; medium-sized cities. 


\section{CONSIDERAÇÕES INICIAIS}

A segregação socioespacial, considerada como parte integrante e fundamental para compreensão da produção do espaço urbano, como abordado na obra de Vasconcelos (2013) e Carlos (2013), tem sido objeto crescente de pesquisas de diversas áreas das ciências sociais. Esse fenômeno urbano, que se manifesta tanto pelo acesso restrito das qualidades urbanísticas como sugere Rolnik (2008), quanto pela desigual exposição aos impactos ambientais como aponta Acselrad (2007), ainda está longe de ser esgotada.

A dinâmica de expansão das cidades brasileiras tem passado por um processo transformativo consequente de uma expansão pautada nos interesses do mercado imobiliário, seja na produção habitacional para a população de baixa renda, seja na produção desenfreada de empreendimentos habitacionais fechados que tem como foco a população de rendas mais altas. De acordo com Sposito (2007), é parte desse processo a acentuação das formas de apropriação segregada do espaço, pois os modelos identificados nas áreas de expansão têm configurado uma morfologia urbana cada vez mais descontínua e fragmentada. Nesse sentido, as transformações urbanísticas têm contribuído para profundas alterações nas configurações urbanas, intensificando o fenômeno da segregação socioespacial nas cidades brasileiras, sejam elas metropolitanas ou não.

Com o crescimento populacional provocado pelo deslocamento das atividades produtivas do setor industrial, as cidades de médio porte têm assistido uma expansão física do seu território que, associado às novas estratégias do mercado imobiliário, as áreas urbanas dessas cidades não escaparam dos conflitos territoriais da realidade brasileira, e a expansão física dessa nova dinâmica urbana tem se baseado na expansão horizontal do território urbanizado e na urbanização dispersa (CALDEIRA, 2000; SPOSITO, 2007).

Dentre as pesquisas que buscam investigar os impasses existentes nas cidades, Pereira et al (2011) destacam o grande interesse em tratar essa problemática com uso da abordagem da Sintaxe Espacial, também conhecida como Análise Sintática do Espaço ou Teoria da Lógica Social do Espaço, criada na década de 1970 pelos pesquisadores Bill Hillier e Juliene Hanson, na University College London (UCL/Londres - Inglaterra), e teve como colaboradores pesquisadores de diversos países, incluindo pesquisadores brasileiros. De acordo com Netto (2013, p. 1) ao investigar os fenômenos urbanos a partir da teoria da Sintaxe Espacial é possível proporcionar "um amparo empírico em um campo da prática marcado por abordagens normativas amplamente baseadas em inferências nunca verificadas". Para o autor, a Sintaxe Espacial se apresenta como uma novidade nas abordagens socioespaciais frente o cenário teórico dos estudos urbanos e acredita que a aplicação dessa teoria, seja capaz de traduzir com mais clareza a interferência que o modelo de organização espacial tem sobre a vida social.

O aparente diálogo da teoria da Sintaxe Espacial com o conceito de Segregação Socioespacial ocorre porque ambos abordam a dimensão social e espacial e, considerando esse vínculo o trabalho tem como objetivo demonstrar como a Segregação Socioespacial acontece sob o ponto de vista configuracional mediante o potencial metodológico da Sintaxe Espacial, tendo como objeto de estudo a cidade de São Carlos, cidade de porte médio brasileira, localizada na região central do estado de São Paulo.

Assim, acredita-se que as porções do tecido urbano situados nas áreas mais excluídas do ponto de vista socioeconômico também sejam caracterizadas por fortes descontinuidades configuracionais que, por sua vez, acabam intensificando as disparidades dessas áreas com as áreas mais incluídas, seja do ponto de vista socioeconômico, seja do ponto de vista configuracional.

Para alcançar o objetivo proposto, a metodologia utilizada foi dividida em três etapas:

$1^{\circ}$ - leitura teórica, onde foram consultados materiais bibliográficos acerca das temáticas de segregação socioespacial e a teoria da sintaxe espacial;

$2^{\circ}$ - sistematização das informações do objeto de estudo, a partir do mapa axial da cidade de São Carlos (disponibilizado pelo doutorando Timóteo Schroeder - Programa de Pós-Graduação em Arquitetura e 
Urbanismo - UFSC); tal mapa axial foi utilizado para a espacialização de dados - no software QGis e plug-in Space Syntax Toolkit - relativos à renda média dos moradores de São Carlos e à densidade demográfica nos setores censitários do município, disponibilizados pelo Instituto Brasileiro de Geografia e Estatística (IBGE); posteriormente, os dados foram selecionados conforme sua importância de cruzamento, a fim de identificar a lógica de produção do espaço urbano existente, a partir das correlações de valores.

$3^{\circ}$ - analisar os resultados obtidos no estudo sobre a cidade de São Carlos para verificar a hipótese e discutir o objetivo da pesquisa, assim como tecer algumas considerações da segregação socioespacial sob o ponto de vista configuracional.

Diante do contexto anteriormente exposto, o presente artigo pretende abordar a temática da segregação socioespacial, apresentando-a como uma parte importante para compreensão da produção do espaço urbano, demonstrando que esta ocorre em decorrência dos interesses de mercado - que tem como foco na população de maior renda -, explorando a influência do setor industrial aliado ao aumento populacional, explicando como estes fatores vem alterando a estrutura espacial em São Carlos.

\section{SEGREGAÇÃO SOCIOESPACIAL E A LÓGICA DA SINTAXE ESPACIAL}

Com base nos estudos de Corrêa (1989), o primeiro modelo de segregação foi definido pelo geógrafo alemão J. G. Kohl em 1841, onde a cidade era dividida entre a classe alta, que vivia no centro, e a classe mais baixa que moravam nas periferias. No entanto, Vasconcelos (2004) comenta que o tema da segregação socioespacial aparece pela primeira vez na literatura acadêmica através dos trabalhos produzidos pela Escola de Chicago e destaca os trabalhos de R. Park, E. Burgess e R. McKenzie que abordavam a segregação socioespacial como um fator natural da urbanização.

Contrariando o pensamento da Escolha de Chicago, Vieira e Melazzo (2003) afirmam que o conceito de segregação socioespacial passa a ter intensa influência do pensamento marxista e identificam os trabalhos de Jean Lojkine, Manuel Castells e Henri Lefebvre como os principais estudiosos desse pensamento.

A pesquisa citada acima aponta que, para Lefebvre, na sociedade capitalista, a organização do espaço urbano é uma forma de produção social que tem como base três condicionantes importantes. A primeira refere-se ao espaço urbano tratado como uma mercadoria, a segunda acontece em decorrência da primeira, que produz um acesso desigual aos espaços urbanos determinados de acordo com a classe social, e por fim, o autor acredita que, em decorrência das duas primeiras condicionantes, a apropriação do espaço acaba assumindo um tratamento ideológico.

Ao tratar da questão urbana, Castells (1983) analisa o processo de segregação socioespacial como efeito da distribuição espacial das classes sociais bem como o acesso desigual dos serviços coletivos. Para esse autor, a segregação residencial tem uma expressão forte quando há uma tendência à diferenciação social, que se reflete no espaço de forma intensa. Para Lojkine (1997), a forma como o espaço urbano se organiza sob o modelo de produção capitalista é o que resulta na divisão social do espaço nas cidades.

Ao analisar a segregação por uma vertente econômica, Villaça (2001, p. 142) faz uma associação entre classes sociais e moradia. Segundo o autor, a segregação é parte de um processo em que "... diferentes classes ou camadas sociais tendem a se concentrar cada vez mais em diferentes regiões ou conjuntos de bairros da metrópole". No entanto, a distribuição das classes sociais no espaço admite a presença da classe mais alta na periferia e da classe mais baixa no centro, e que ele denomina de centro nas periferias e periferias no centro.

As desigualdades sociais, conforme aponta Vasconcelos (2013), se refletem na construção do espaço urbano e as formas decorrentes desse processo variam de acordo com as especificidades de cada local. Complementarmente, Côrrea (2013, p. 39) descreve que o espaço urbano de toda sociedade é caracterizado pela fragmentação que, nas palavras do autor significa "áreas distintas entre si no que diz respeito a gênese e a dinâmica, conteúdo econômico e social, paisagem e arranjo espacial de suas formas" 
e, nesse sentido, cada grupo social a representa de forma distinta. Para o autor, a forma mais expressiva que gera a fragmentação é consequente do que ele chama de segregação residencial que se espacializa a partir da homogeneidade de cada grupo social e que apresenta características diversas no que diz respeito, tanto ao padrão habitacional, quanto ao local de inserção urbana (CORRÊA, 1995).

Uma importante referência no estudo que trata das transformações no padrão de segregação no Brasil foi o trabalho de Caldeira (2000) sobre os enclaves fortificados. Nesse estudo, a autora considera que o novo padrão de segregação socioespacial tem marcado as cidades brasileiras através da proximidade física e do distanciamento social, pois, mesmo em casos de proximidades geográficas, as adjacências não se traduzem por interação ou coesão social entre os diferentes grupos sociais. Marques (2014) utiliza o termo evitação social para descrever a proximidade física entre os grupos sociais que não possuem interação social.

O crescimento dos impasses vivenciados nos espaços urbanos tem motivado a busca por novas metodologias e novas escalas para compreender a dinâmica socioespacial nas cidades. De maneira geral, a análise da segregação socioespacial tem como base a leitura de unidades espaciais desarticuladas, como por exemplo, a relação centro-periferia que, para Villaça (2011) se restringe apenas a uma descrição. Por outro lado, a Sintaxe Espacial faz parte de uma corrente que sustenta uma análise mais precisa da configuração urbana a partir dos segmentos de ruas e tem potencial para avaliar a relação entre a segregação e sua totalidade com a estrutura urbana que, de acordo com Villaça (2011), sem essa relação mais ampla esses estudos ficam incompletos. Assim, o uso da Sintaxe Espacial vai de acordo com essa reflexão, pois privilegia a forma-espaço como principal modelo de leitura da configuração urbana e despreza a individualidade, como descreve Medeiros (2006).

A Sintaxe Espacial é fundamentada em uma teoria descritiva do espaço mas pertence à um campo teórico e metodológico denominado como a Lógica Social do Espaço (HILLIER; HANSON, 1984). Para os autores esse instrumental metodológico analisa a organização da cidade a partir de entidades descritivas que possibilitam identificar uma configuração espacial para avaliar as condições tanto para a integração, como para a segregação entre unidades elementares como ruas e praças.

Conforme afirma Medeiros (2006), o campo de investigação da Sintaxe Espacial se insere, principalmente, em torno de questionamentos sobre as maneiras como a configuração do espaço urbano afeta o modo como a cidade funciona e seu grau de influência sobre esse espaço. A Sintaxe Espacial busca, conforme os estudos de Holanda (2002, p. 92), avaliar as implicações sociais do espaço arquitetônico para estabelecer "relações entre a estrutura espacial de cidades e de edifícios, a dimensão espacial das estruturas sociais, e variáveis sociais mais amplas" buscando captar tanto a lógica do espaço arquitetônico quanto a lógica espacial das sociedades.

Pereira et al (2011, p. 8) comentam que de modo geral a "estrutura espacial das cidades" é compreendido sob o nome de configuração urbana e abrange o conjunto de relações entre o padrão existente de barreiras e de permeabilidade que compõem a estrutura física do espaço "onde a forma de disposição espacial relacional desses elementos pode proporcionar maiores ou menores facilidades (e restrições) para a sociedade desempenhar suas atividades no espaço, incluindo a circulação de pessoas", reforçando os pressupostos defendido por Hillier e Hanson (1984) sobre a Sintaxe Espacial ser um instrumental que viabiliza a avaliação das condições de integração e segregação no espaço urbano a partir de valores quantitativos, além da identificação da interferência de diferentes tipos de configurações urbanas.

Em sua pesquisa empírica sobre a Sintaxe Espacial, Holanda (2001) afirma que essa teoria não aborda as unidades de análise de maneira isolada, pois considera fundamental contextualiza-las com base nas relações que cada uma estabelece com outras unidades e, por isso, suas variáveis analíticas buscam ilustrar estas relações. Dessa forma, o espaço urbano passa a ser investigado como um sistema constituído por unidades elementares que se relacionam umas com as outras, como por exemplo, as linhas axiais, que correspondem ao sistema viário, contemplando os veículos e os pedestres, e as unidades convexas que correspondem aos espaços urbanos. Para o autor, a Sintaxe Espacial oferece diversos instrumentos para melhor entendimento e representação do espaço urbano, pois "contempla um método poderoso para estudos do espaço urbano ao possibilitar que fatores relacionados à configuração sejam matematicamente 
mensurados e claramente visualizados" e por isso podem ser correlacionados com outras informações que envolvem os estudos urbanos.

Para realização da análise sintática, Hillier e Hanson (1984) propuseram que o sistema pode ser descrito a partir de espaços convexos ou a partir de espaços axiais. Alárcon (2004) considera o mapa axial como a principal técnica da teoria da Sintaxe Espacial por ser o instrumento mais adequado para verificar a proporção entre a configuração espacial e as expectativas sociais de co-presença e acessibilidade de um local. A aplicação dessa técnica permite avaliar o grau de integração ou segregação das vias, além de relacionar o tipo de usos de uma cidade ao seu uso do solo, em outras palavras, se nas vias mais integradas estão as atividades comerciais e de serviços, e nas vias segregadas os usos residenciais. Medeiros (2006) aponta que existe uma intensa relação entre a forma de articulação das malhas viárias e os potenciais de acessibilidade que podem ser visualizado nos eixos um mapa axial.

Os mapas axiais consistem, de acordo com Pereira et al (2011, p. 9) "no conjunto das vias que compõem o sistema viário da cidade entendidas sob uma perspectiva relacional", e podem ser considerados tanto os aspectos topológicos específicos que cada uma dessas vias estabelece com suas vias mais próximas (conexões locais) quanto a relação que cada uma estabelece em relação a todo o sistema ao qual pertence (conexões globais).

O tema da segregação socioespacial não é novidade, pois já foi amplamente explorado pela literatura acadêmica. No entanto, deve-se destacar que grande parte dos estudos relacionados aos fenômenos urbanos tem privilegiado uma mesma escala de abordagem, ou seja, a metropolitana, como o trabalho de Kowarick (1979), Bonduki e Rolnik (1982), Ribeiro (1997), Caldeira (2000), Villaça (2001), Luco e Vignoli (2003), Gómez Sandoval (2011); Marques (2014), dentre outros. Por esse motivo pode-se afirmar que, apesar de não esgotado, as pesquisas sobre esse tema encontram-se consolidados quando é abordado nos grandes centros urbanos. Paralelamente, já existe diversas pesquisas que oferecem algumas possibilidades de interpretação desse fenômeno em cidades de médio porte, como a de Melazzo (1993), Sobarzo (1999; 2006), Carvalho (2003), BelletSanfeliu e LlopTorné (2004), e Spósito (2007; 2013), mesmo que no que se refere ao estudo da segregação socioespacal em cidades médias, ainda encontram-se em desenvolvimento.

Ao dar ênfase às análises e reflexões em cidades desse porte, Sposito (2007) comenta que as apropriações do solo urbano nas áreas de expansão dessas cidades têm reconfigurado o padrão de segregação socioespacial de forma que, tal fenômeno, requer uma melhor compreensão acerca de suas formas e sua espacialização. Assim, diante do exposto, uma questão importante do presente artigo em seu enfoque empírico é o de identificar se a configuração espacial das cidades pode aumentar o padrão de segregação socioespacial.

\section{REDISTRIBUIÇÃO DA ATIVIDADE INDUSTRIAL NOS MUNICÍPIOS BRASILEIROS}

O crescimento e a expansão das áreas urbanas, em meados do século $X X$, foram marcados pela concentração e superpovoamento em decorrência do desenvolvimento econômico associado à intensificação da atividade industrial concentrada nos grandes centros urbanos. No decorrer desse século, o crescimento populacional nas cidades foi tão significativo que o país iniciou o século XX com quase $10 \%$ da população nas cidades e finalizou com 81\% (MARICATO, 2006; OLIVEIRA, 2001).

No entanto, como expõe Carlos (2011, p. 113) "em cada momento histórico o ciclo do capital envolve condições diferenciadas para sua realização" e nesse contexto, o Brasil tem assistido um conjunto de transformações espaciais urbanas influenciadas por determinações de ordem econômica, associado às novas opções locacionais da indústria e, com isso, as cidades de médio porte têm intensificado sua importância na estrutura da rede urbana, além de terem um aumento na taxa geométrica de crescimento populacional.

A expansão do crescimento populacional nessas cidades faz parte do processo de redistribuição da população urbana, que teve início entre as décadas de 1970 e 1980. Contudo, esse novo padrão de 
urbanização tornou-se mais evidente a partir dos dados do Censo Demográfico de 1991, onde as regiões metropolitanas deixaram de apresentar as maiores taxas de crescimento, confirmando a nova tendência de distribuição populacional. Essas estimativas ficam evidentes no Gráfico 1, que identifica que a primeira maior taxa geométrica de crescimento populacional está nos municípios de porte médio (aqueles que possuem entre 100 mil e 500 mil habitantes), entre os anos 2013 e 2014 e, em segundo, mas com uma diferença pequena, está nas cidades de pequeno porte (aqueles com população entre 50 mil e 100 mil habitantes).

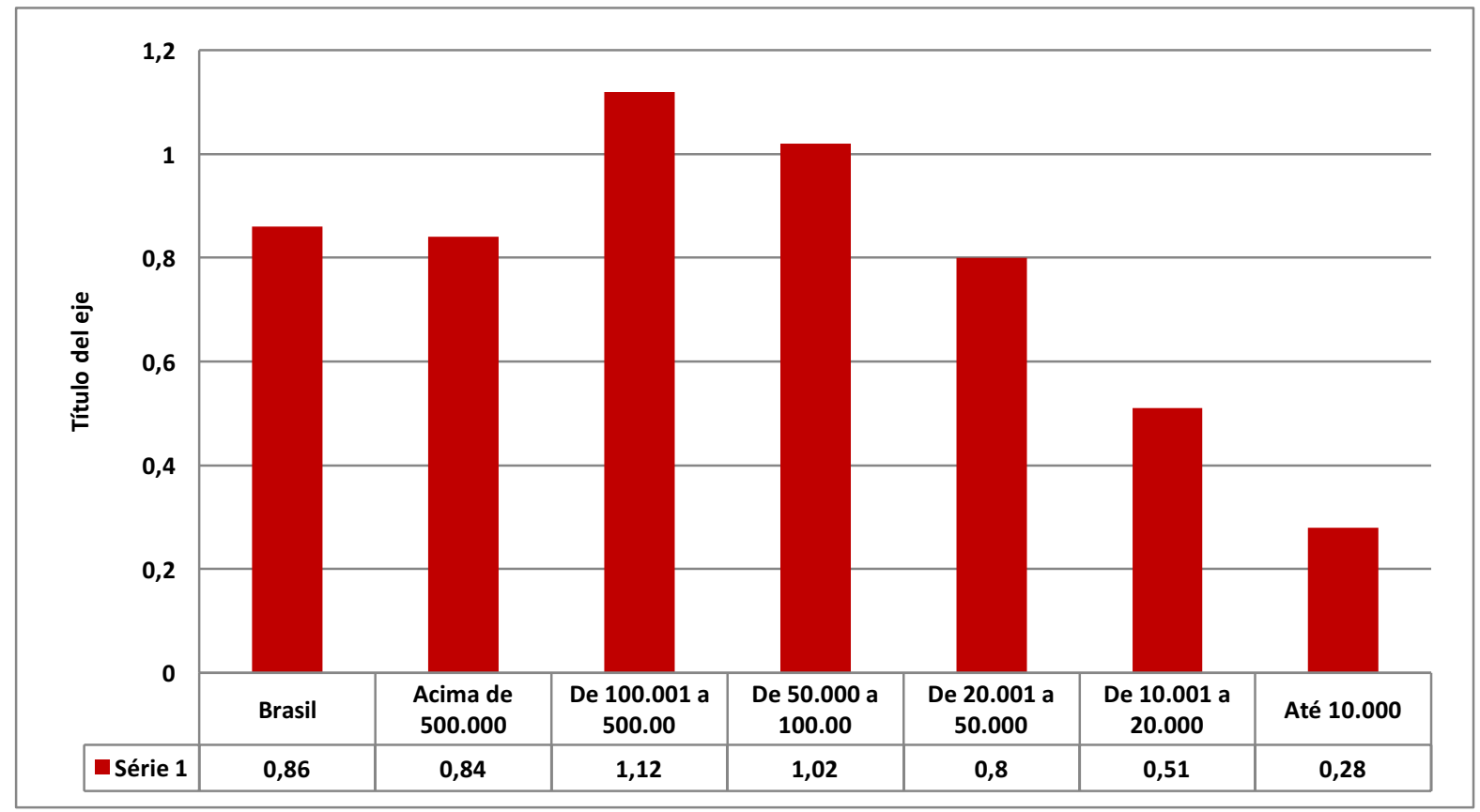

Gráfico 1 - Taxa geométrica de crescimento por classe de tamanho de município (IBGE, 2014).

Elaboração dos autores a partir dos dados do IBGE

É possível afirmar, portanto, que atualmente o Brasil mantém as mesmas características na dinâmica demográfica das últimas décadas, consolidando as tendências migratórias nessas cidades que ainda crescem mais que os grandes centros urbanos. Para Santos (2010) as cidades que apresentam um crescimento do seu peso demográfico também tendem a apresentar uma dinâmica econômica mais fortalecida e diversificada. A Figura 1 mostra que as cidades médias paulistas têm desempenhado um papel fundamental na reestruturação econômica em detrimento da reorganização do setor produtivo intensificou a industrialização das cidades do interior paulista, produzindo, simultaneamente, modificações de cunho urbanístico. 


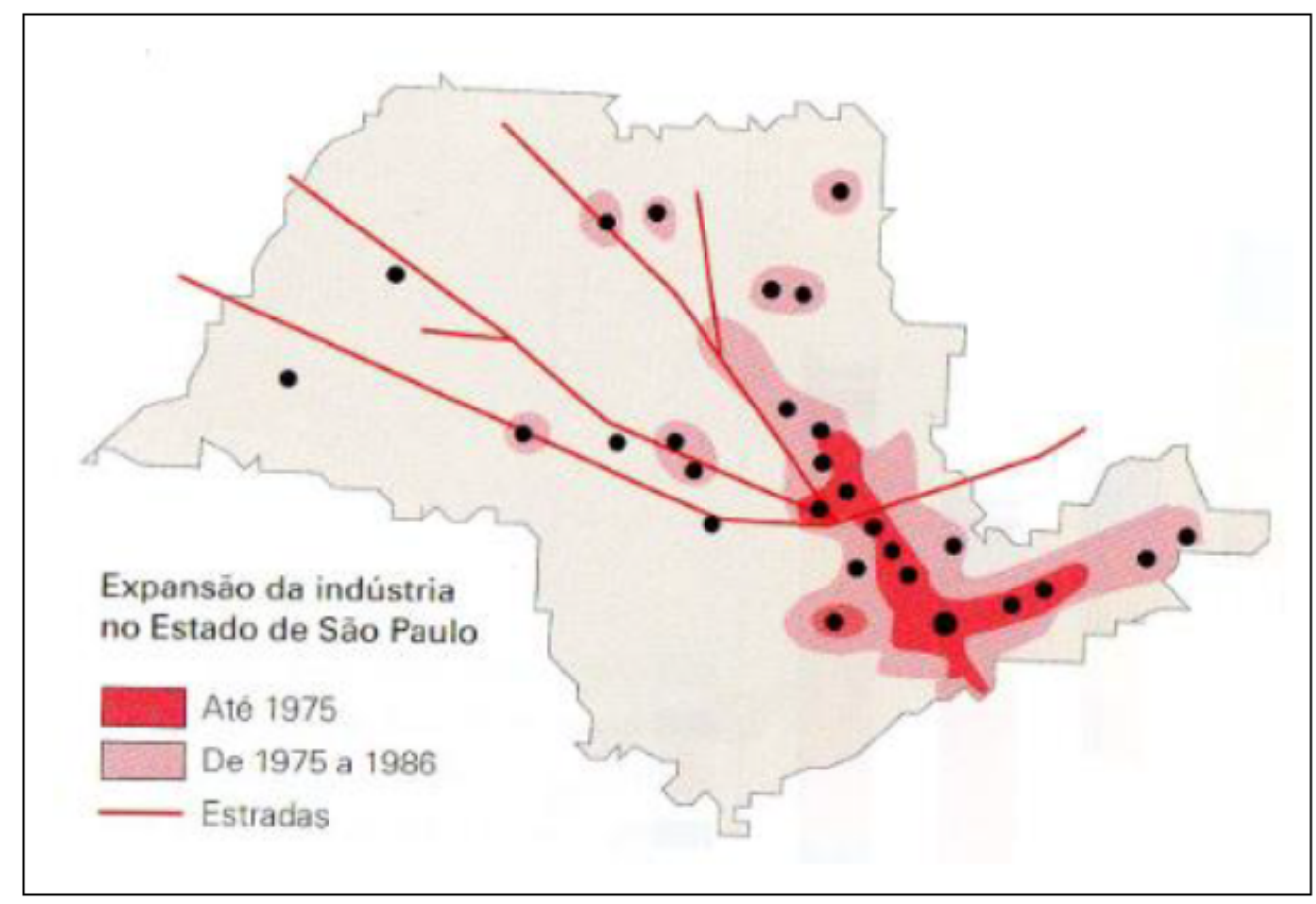

Figura 1 - Expansão da indústria no estado de São Paulo (THÉRY E MELLO, 2014)

Ao tratar sobre o processo de desconcentração produtiva, Santos (2011, p. 8) afirma que a desconcentração espacial da população "tende a acompanhar a criação de oportunidades de emprego". Desta forma, é importante ilustrar, em paralelo à análise dos novos indicadores de distribuição espacial da população, a avaliação dos locais que apresentam um crescimento na geração de emprego na indústria, para que possam contribuir também ao retratar as alterações locacionais desse setor, como pode ser identificado na Tabela 1.

\begin{tabular}{|c|c|c|c|c|c|c|c|c|}
\hline SETOR & \multicolumn{2}{|c|}{ INDÚSTRIA } & \multicolumn{2}{c|}{ COMÉRCIO } & \multicolumn{2}{c|}{ SERVIÇO } & \multicolumn{2}{c|}{ CONST. CIVIL } \\
\hline ANO & 1991 & 2010 & 1991 & 2010 & 1991 & 2010 & 1991 & 2010 \\
\hline RM & 1.459 .414 & 1.188 .683 & 523.789 & 1.287 .649 & 2.148 .116 & 4.274 .549 & 213.400 & 404.247 \\
São Paulo & & & & & & & & \\
\hline São Carlos & 18.577 & 19.993 & 5.224 & 13.798 & 8.034 & 30.459 & 1.008 & 2.703 \\
\hline
\end{tabular}

Tabela 1 - Comparativo de empregos gerados pela indústria na cidade de São Carlos e na Região Metropolitana de São Paulo (SEADE ,2016).

Elaborado pelos autores com base nos dados do Seade.

A análise comparativa do desempenho da criação de empregos desses setores da economia, com base nos dados da Região Metropolitana de São Paulo e de São Carlos, permite ilustrar duas modificações mencionadas anteriormente. A primeira refere-se à distribuição espacial dos empregos gerados no setor da indústria, elucidando que as cidades de porte médio têm sido os locais onde a dinâmica industrial tem se fortalecido pelo crescente número de empregos formais e, em contrapartida, verifica-se uma diminuição das oportunidades de empregos desse setor na RMSP. A segunda, refere-se à análise dos dados de outros setores da economia em que São Carlos também têm apresentado um crescimento significativo na oferta de trabalho no setor comércio e serviços, o que ilustra, portanto, a dinâmica econômica em crescimento no país. Assim, é possível dizer que as cidades médias são protagonistas relevantes na dinâmica econômica 
da rede urbana paulista, uma vez que apresentam um expressivo crescimento nas oportunidades de empregos, tendo como destaque os setores da industriai, de comércio e prestação de serviços.

Ainda diante desses dados, é importante salientar o que Lencioni (2003, p. 467) observa acerca de uma leitura simplista do tema da interiorização da indústria, pois, apesar dessas cidades apresentarem um crescimento na oferta de empregos nesse setor, a Região Metropolitana de São Paulo ainda mantém sua relevância na escala do país, o que aconteceu, segundo a autora, foi um espraiamento da atividade industrial.

Os padrões demográficos das cidades de médio porte apresentam ritmos que merecem ser analisados a partir da descentralização da indústria, confirmando a intrínseca relação existente entre o processo de desconcentração industrial com a dinâmica demográfica em que a população acompanha o crescimento das oportunidades de empregos e o caso de São Carlos torna-se bastante ilustrativo nesse sentido. A desconcentração da população urbana pode ser analisada no Gráfico 1 que compara os dados de crescimento da Região Metropolitana de São Paulo com a cidade de São Carlos, confirmando que o crescimento populacional das cidades médias não metropolitanas são superiores em relação à população da RMSP.

A partir da Taxa Geométrica de Crescimento Populacional de São Carlos - SP é possível verificar que São Carlos apresenta uma taxa bastante próxima à taxa de São Paulo na década de 1970. No entanto, desde os anos de 1980, verifica-se um crescimento superior, mas ocorre associado à desaceleração generalizada do crescimento populacional do país. Nesse sentido, a taxa em São Carlos entre 1980 e 1991 foi de 2,84\%, decrescendo entre 1991 à 2000 para 2,01, e entre 2000 e 2010 a taxa foi de $1,41 \%$.

Ao tratar sobre o processo de desconcentração produtiva, Cano (2008) define o período compreendido entre a década de 1970 e 1980 como um período de "desconcentração virtuosa", e identifica dois movimentos que aconteceram simultaneamente, onde parte desse deslocamento tem origem no Estado de São Paulo e segue em direção a outras regiões do país, com ênfase para o Norte do Brasil, e outra parte desse deslocamento tem origem na Grande São Paulo, mas seu fluxo tem como destino o interior paulista. A Figura 2 é bastante ilustrativa desse processo, pois identifica os movimentos urbanos no país, principalmente a partir do estado de São Paulo apontando as regiões e áreas de destino dos migrantes.

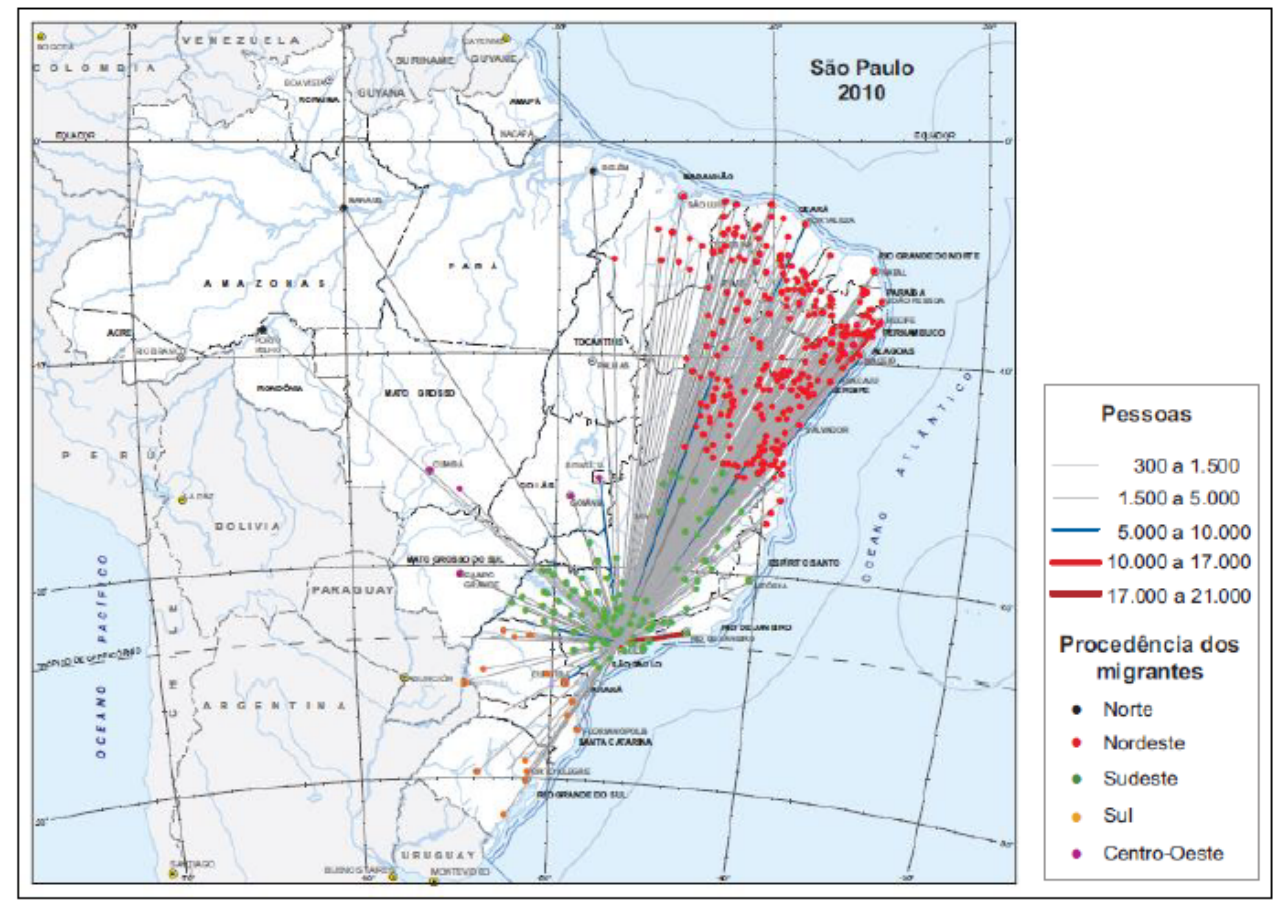

Figura 2 - Procedência dos migrantes do estado de São Paulo (IBGE, 2010) 
São Carlos pertence ao estado de São Paulo que se caracteriza pela concentração máxima do país e por isso a Taxa Geométrica de Crescimento Populacional de São Carlos e de São Paulo está inserida em um contexto de desconcentração da população urbana na capital paulista, que deixou de ser o eixo migratório principal, e por isso as cidades de porte médio como São Carlos passou a apresentar um crescimento populacional superior, confirmando o processo de redistribuição da população.

Diante do contexto apresentado, é possível afirmar que a leitura da atual dinâmica de distribuição dos empregos formais da indústria somado ao crescimento da dinâmica econômica de comércio e serviço, é reveladora do impacto que essas cidades têm provocado no seu novo papel econômico em sua rede urbana, assim como no seu crescimento populacional bem como na estrutura espacial dessas cidades.

\section{ANÁLISE SINTÁTICA DA SEGREGAÇÃO SOCIOESPACIAL EM SÃO CARLOS - SP}

São Carlos é uma cidade de médio porte brasileira, localizada na região centro oeste do estado de São Paulo à uma distância $228 \mathrm{~km}$ (quilômetros) da capital paulista, conforme apresentada na Figura 3. O município possui 243.765 mil habitantes, de acordó com o Instituto Brasileiro de Geografia e Estatística (IBGE, 2016), uma área de 1.136,907 km² (quilômetros quadrados), constitui um importante centro universitário de formação e pesquisa relacionadas à ciência e tecnologia. São Carlos conta a com a presença de duas universidades públicas, a USP (Universidade de São Paulo) e a UFSCar (Universidade Federal de São Carlos), além da atuação de duas unidades da Embrapa (Instrumentação Agropecuária e Pecuária Sudeste).
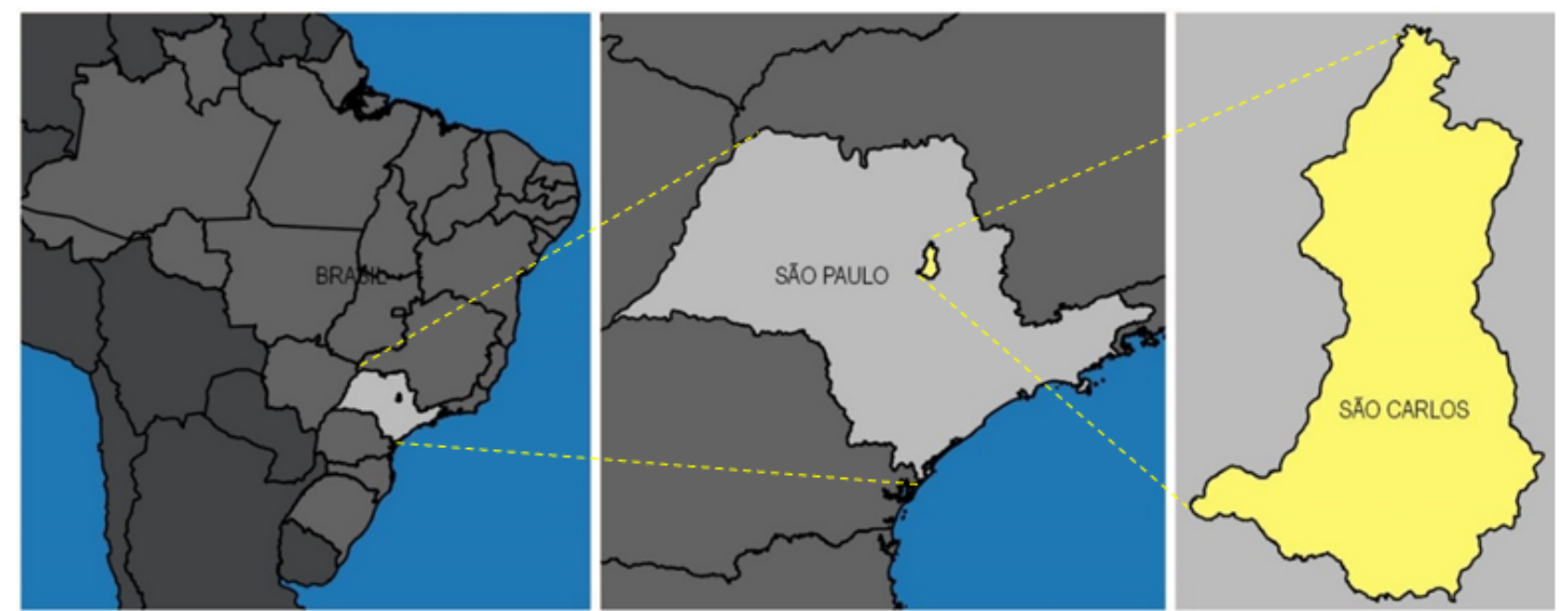

Figura 3: Localização do município de São Carlos - SP (IBGE ,2013).

Elaborado pelos autores e base disponibilizada pelo IBGE.

Para iniciar os procedimentos metodológicos da terceira etapa do presente trabalho, o mapa axial de São Carlos foi disponibilizado pelo doutorando Timóteo Schroeder, do Programa de Pós-Graduação em Arquitetura e Urbanismo, da Universidade Federal de Santa Catarina (PósArq/UFSC). Posteriormente, neste mapa axial, foram espacializados os dados relativos à renda média dos moradores e à densidade demográfica nos setores censitários da cidade estudada. Desta forma, foi possível correlacionar os dados às medidas configuracionais, a fim de identificar a lógica de produção do espaço urbano existente, a partir das correlações de valores.

Ao iniciar a análise desta etapa (Mapas 1 e 2), a primeira correlação realizada foi para verificar onde as populações de maior e de menor renda tem se inserido na cidade e qual a relação existente das classes econômicas com toda a cidade, a partir da configuração espacial. A primeira constatação identificou que em a população de maior renda configura alguns extremos geográficos e que não estão inseridos exclusivamente nas áreas mais centrais. Assim, os dados censitários mais recentes demonstram que já não 
vigora a correlação inequívoca entre centro e população de rendas mais altas, em detrimento da periferia e população de rendas mais baixas.

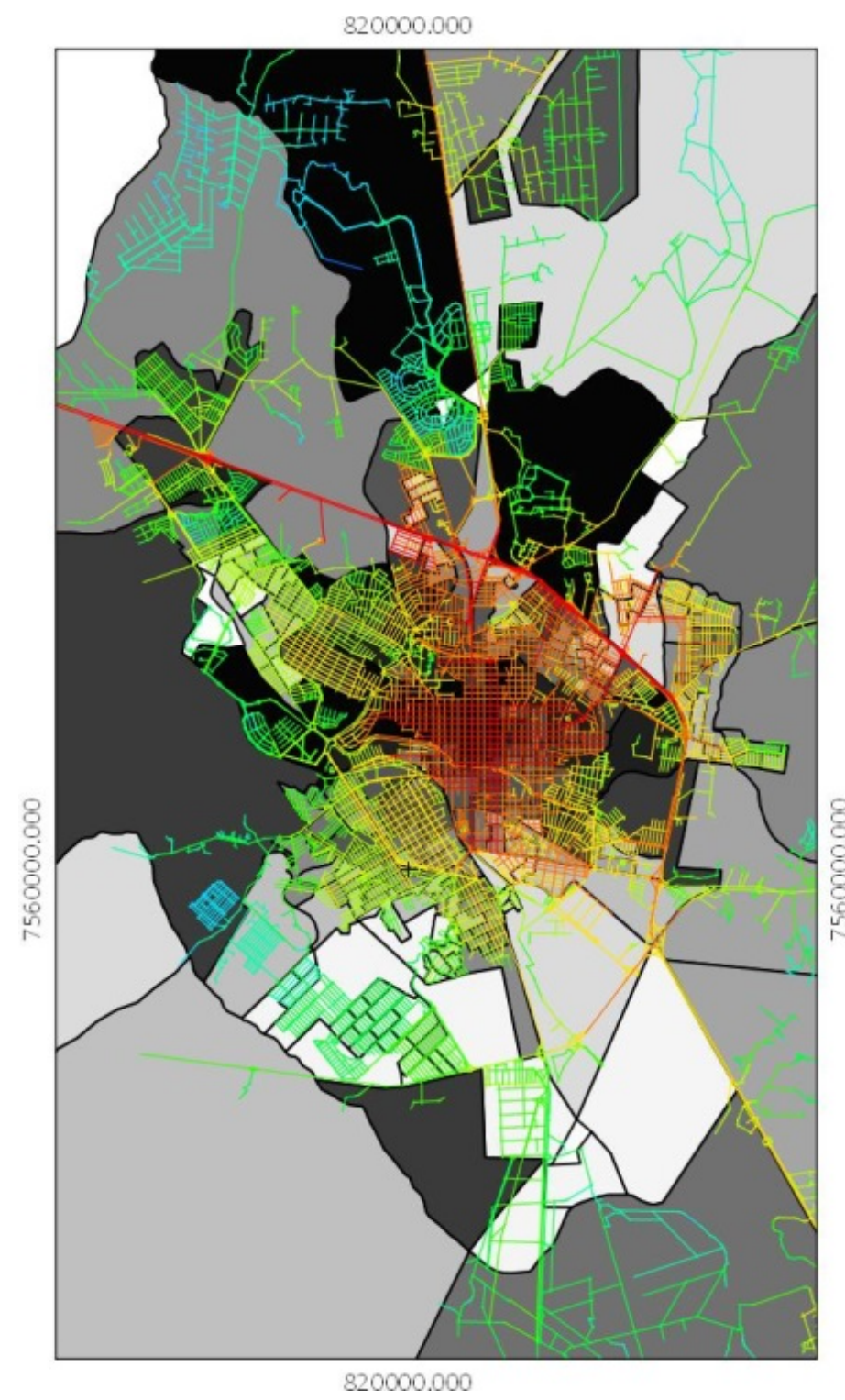

\section{INTEGRAÇÃO X RENDA \\ SÃO CARLOS - SP}

\section{LEGENDA:}

Renda por Setor Censitário

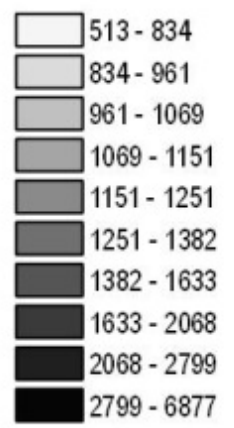

Integração Global (Rn)

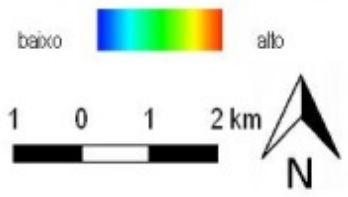

FONTE DE DADOS:

Estados, Brasil; Malha

Municipal Dig. - 2013,

IBGE

Sist Referência: SIRGAS

200023 S

Sist Projeção: UTM

Set/2016

Mapa 1: Integração X Renda de São Carlos - SP

Fonte: Schroeder (2015) e IBGE (2010).

Elaborado pelos autores com base nos dados disponíveis no IBGE.

Do ponto de vista configuracional é possível identificar no Mapa 1, que ilustra os níveis de integração e segregação das vias da cidade, que a população de menor renda situada no setor periférico sudoeste apresenta seus aspectos configuracionais segregados da mesma forma que a população de maior renda, que configura os setores periféricos do extremo norte da cidade, também apresentam aspectos configuracionais segregados. Em contrapartida, os setores de maior integração, denominado pela teoria como núcleo de integração, estão concentrados na área mais central da cidade. Do ponto de vista da sintaxe isso se traduz em espaços onde são acessados mais fácilmente que os demais. No entanto, o mapa 2, que ilustra os eixos de maior e menor escolha algumas observações devem ser ponderadas em relação à implantação das diferentes classes econômicas. 


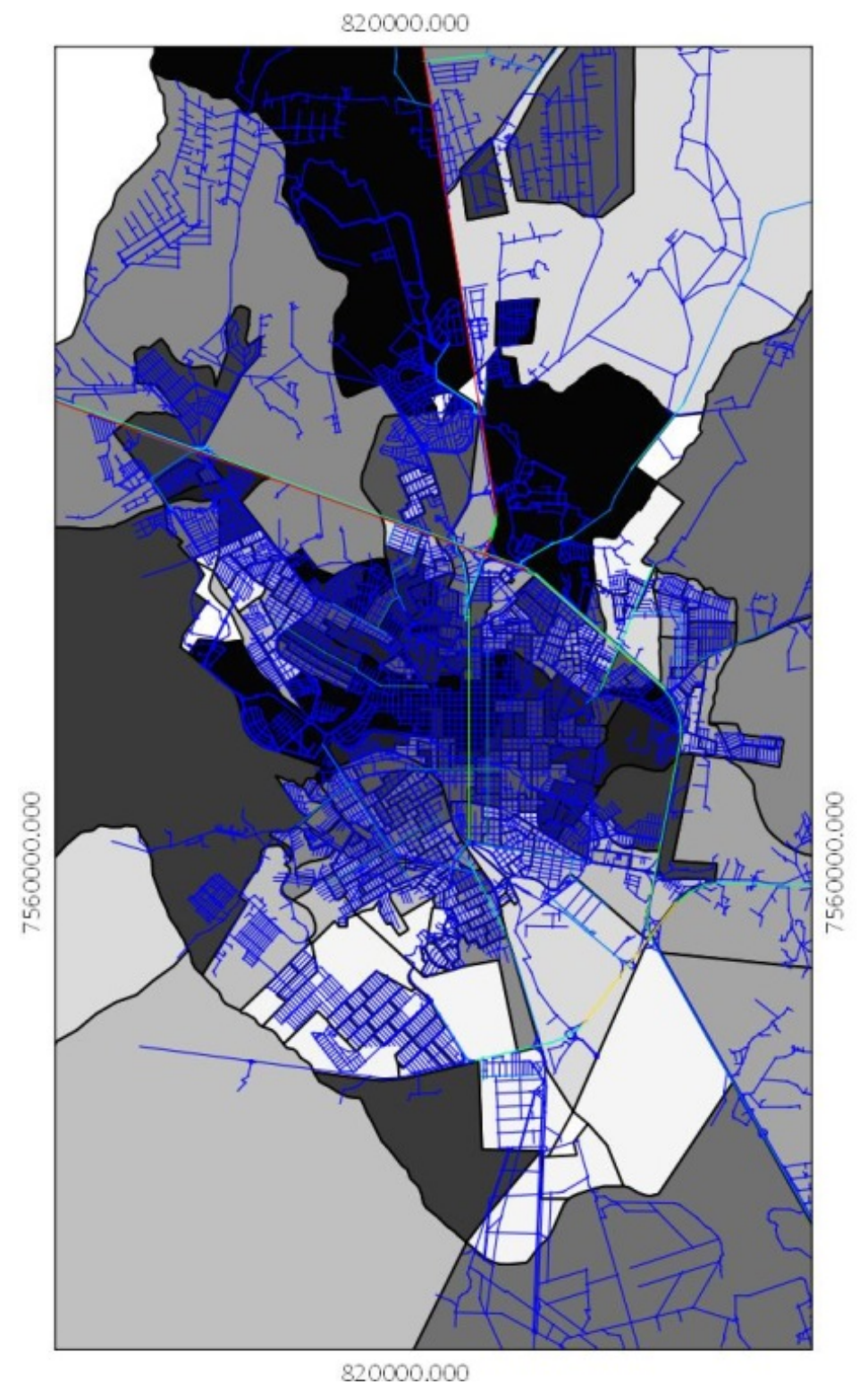

\section{ESCOLHAX RENDA \\ SÃO CARLOS - SP}

\section{LEGENDA:}

Renda por Setor Censitário

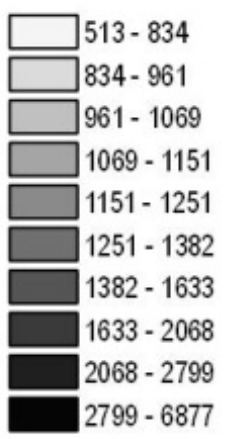

Escolha Global (Rn)

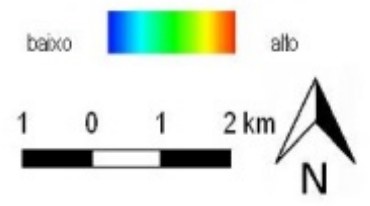

\section{FONTE DE DADOS:}

\section{Estados, Brasil; Malha}

Municipal Dig. - 2013,

IBGE

Sist Referência: SIRGAS

$200023 \mathrm{~S}$

Sist Projeção: UTM

Set./2016

Mapa 2: Escolha X Renda de São Carlos - SP

Fonte: Schroeder (2015) e IBGE (2010)

Elaborado pelos autores com base nos dados disponíveis no IBGE.

A população de maior renda, situada em áreas segregadas do ponto configuracional no setor norte como mostrou o mapa 1, está inserida próxima ao eixo de maior escolha da cidade ilustrado pelo Mapa 2. Esta constatação identifica que a população de alta renda está conectada a um sistema rodoviário importante já que esse setor está vinculado a rodovia estadual SP-316, que atua como continuidade da Avenida São Carlos, identificada como o eixo de mais alta escolha da cidade. Já os espaços destinados para a população de menor renda, como no setor sudoeste, apresentam também baixa acessibilidade em relação ao sistema urbano como um todo. Diante disso é possível afirmar que quanto maior é a renda, maior é a facilidade de deslocamento e, consequentemente, maior integração ao espaço urbano

A dinâmica demográfica enquanto variável analítica também pode contribuir para o entendimento da segregação socioespacial a partir de sua espacialização. Em São Carlos, a dinâmica demográfica na escala da cidade passou por algumas transformações que revelam tanto a permanência do crescimento periférico 
em alguns setores da cidade, como uma tendência de crescimento populacional em alguns setores periféricos a partir de uma nova dinâmica imobiliária, conforme aborda Siqueira (2015).

No que diz respeito às áreas de expansão, a periferia norte, noroeste e oeste da cidade apresentam setores que se diferenciam pela densidade, mas que devem ser apresentadas algumas outras observações. Em São Carlos, esas áreas são caracterizadas pela proliferação de empreendimentos habitacionais fechados destinados para renda média e alta que têm marcado um crescimento horizontal sob baixa densidade, conforme ilustrado pela Figura 4.

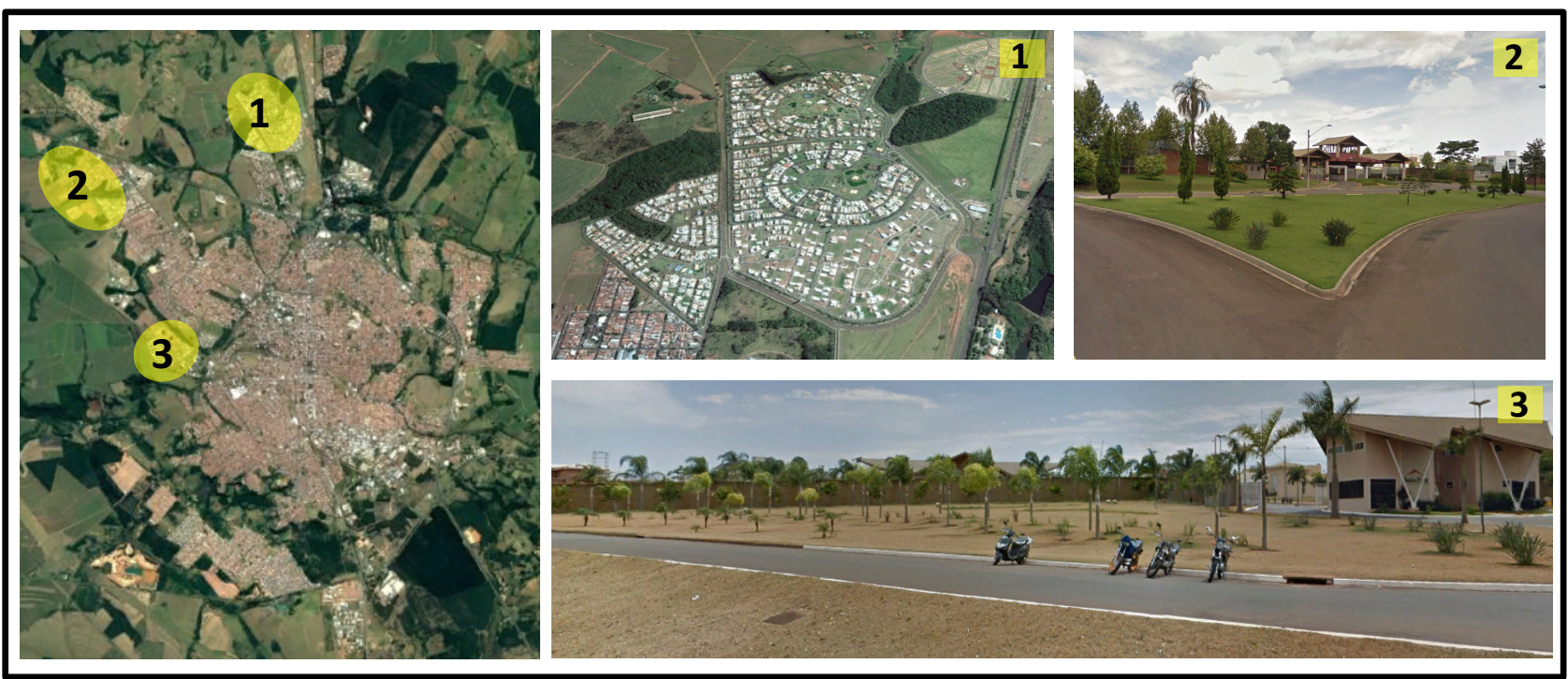

Figura 4: Expansão horizontal em São Carlos - SP

Fonte :Google Maps/Street View ( 2017).

A Figura 4 mostrou que em São Carlos essas bordas urbanas são constituídas básicamente por empreendimentos de média e alta renda que possuem lotes grandes e que, geralmente são ocupados por núcleos familiares pequenos. Em contraponto, a região sul/sudoeste apresentam setores de maior densidade pois se expande essencialmente pela implantação de conjuntos habitacionais de alta densidade e baixo padrão que são destinados para a população de menor renda, conforme ilustra a Figura 5. Esses conjuntos tem intensificado a densidade dessa região, reforçando a concentração populacional nessas áreas que possuem lotes pequenos para núcleos familiares numerosos.

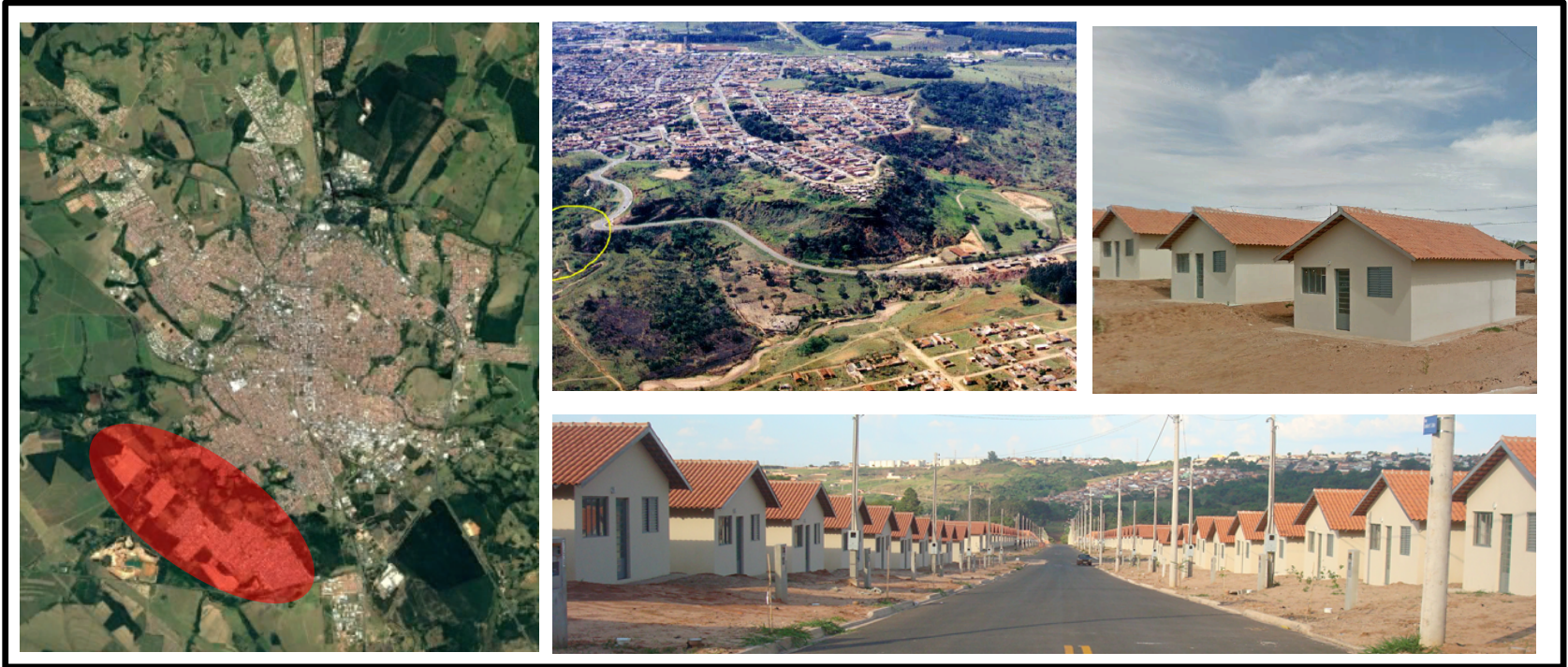

Figura 5: Expansão horizontal em São Carlos - SP

Fonte: Google Maps/Street View (2017) e Arquivo TEIA. 
Do ponto de vista configuracional, em São Carlos (Mapa 3), os dois eixos de alta escolha referem-se às rodovias que atravessam pelo setor norte e noroeste da cidade e coincide com a área que têm se expandido sob baixa densidade a partir da implantação de empreendimentos imobiliários como ficou ilustrado nas Figura 4. Já os setores sul e sudoeste que se expandam sob alta densidade não estão inseridos próximos à eixos que facilitam seu acesso à cidade, conforme a Figura 5.

No Mapa 4, elaborado para analisar a densidade na cidade de São Carlos, fica evidente que as áreas de maior densidade encontram-se bastante dispersas no tecido urbano, apresentando algumas peculiaridades. Em São Carlos, a área mais central apresenta baixa densidade e tal fato ocorre pela migração da população das áreas mais centrais para as áreas de expansão periférica do setor norte e noroeste, com a finalidade de morar em empreendimentos habitacionais fechados, que corresponde ao eixo de inserção das famílias de rendas mais altas.

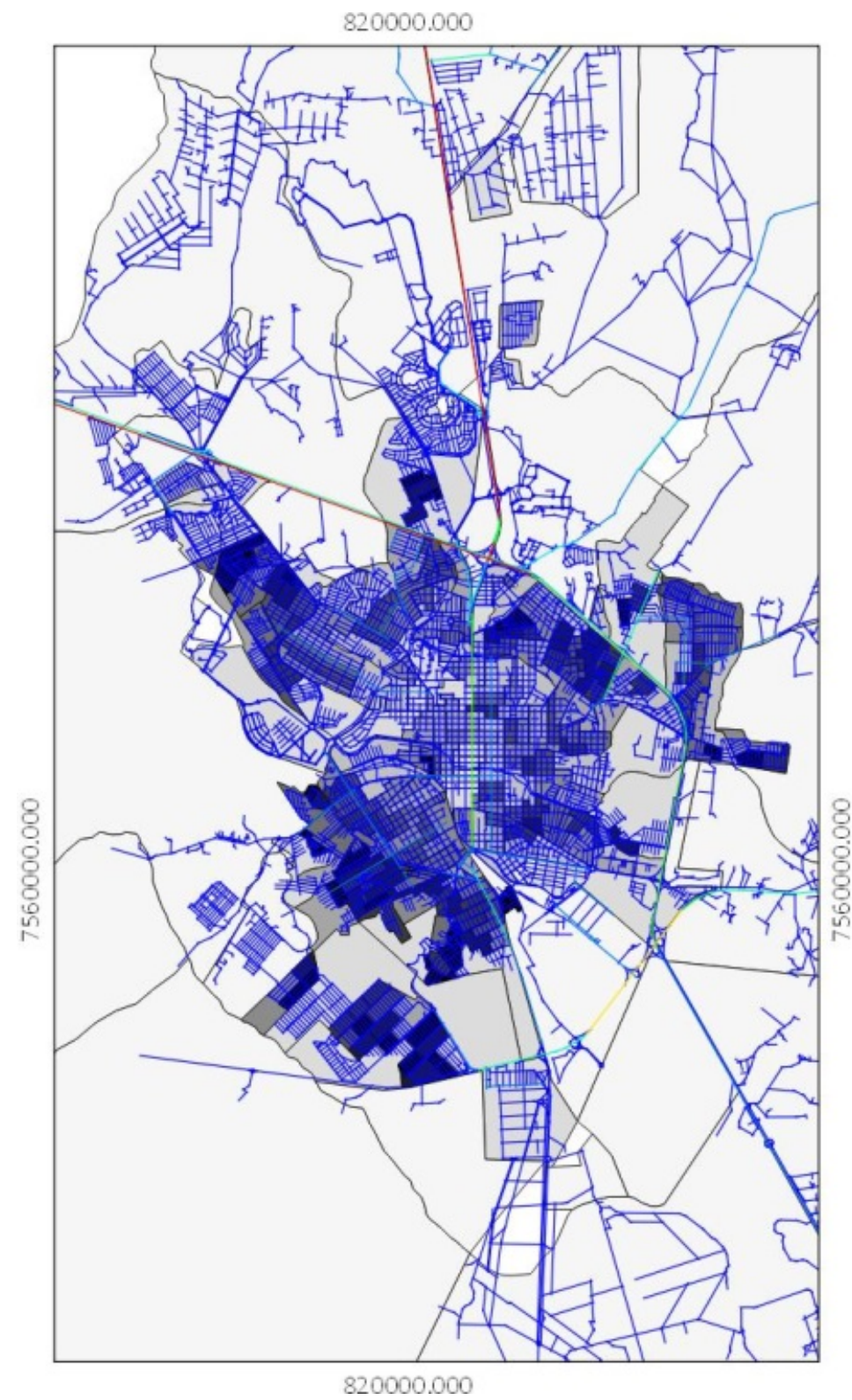

\section{ESCOLHAX DEMOGRAFIA SÃO CARLOS - SP}

\section{LEGENDA:}

Demografia por Setor Censitário

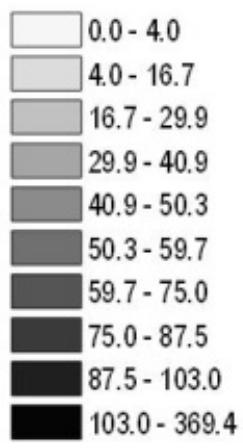

\section{Escolha Global (Rn)}

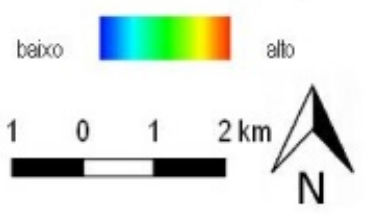

\section{FONTE DE DADOS:}

Estados, Brasil; Malha Municipal Dig. - 2013,

IBGE

Sist Referência: SIRGAS

$200023 \mathrm{~S}$

Sist Projeção: UTM

\section{Set/2016}

Mapa 3: Escolha X Demografia de São Carlos - SP

Fonte: Schroeder (2015) e IBGE (2010)

Elaborado pelos autores com base nos dados disponíveis no IBGE. 


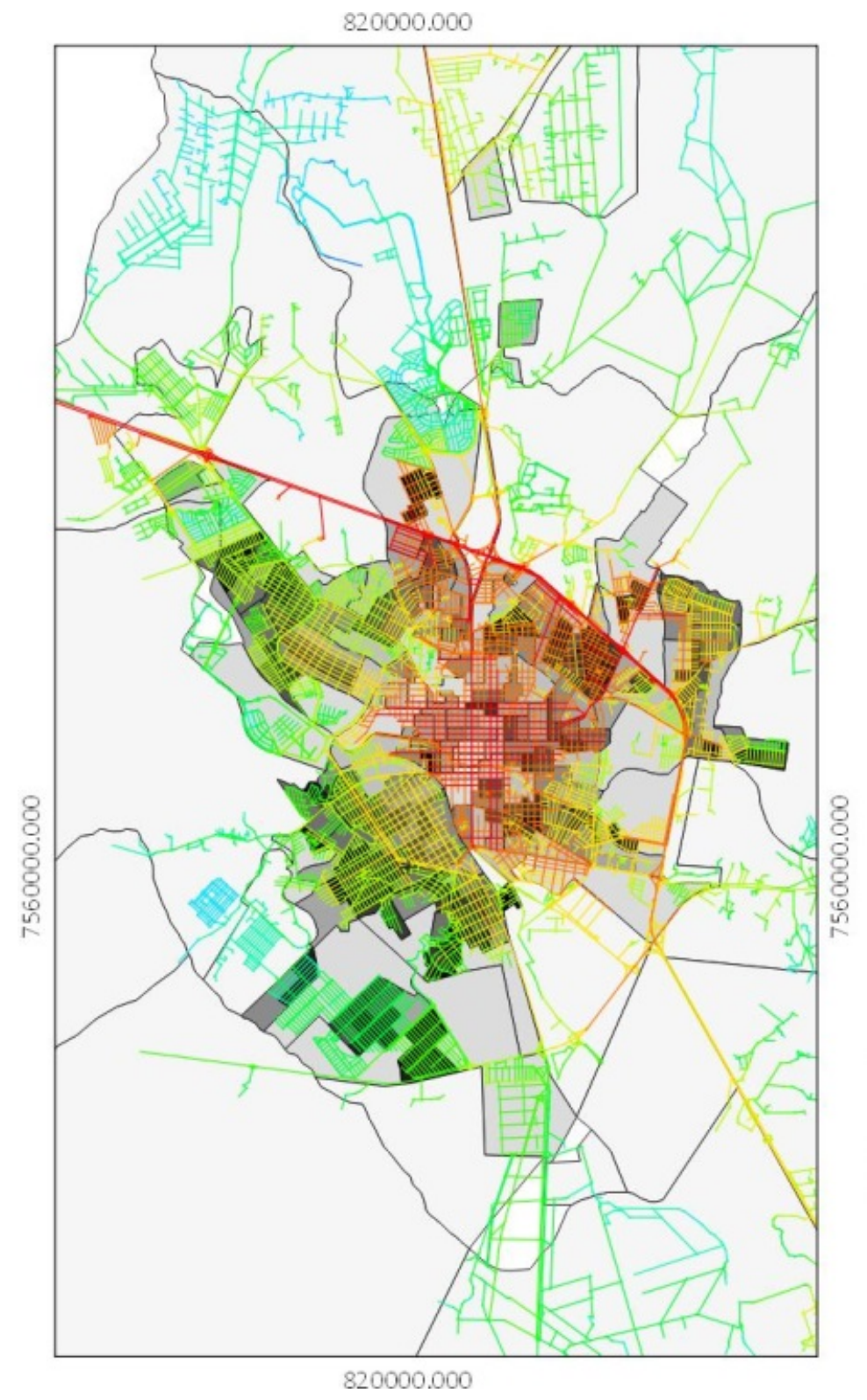

\section{INTEGRAÇ̃̃OX DEMOGRAFIA \\ SÃO CARLOS - SP}

\section{LEGENDA:}

Demografia por Setor Censitário

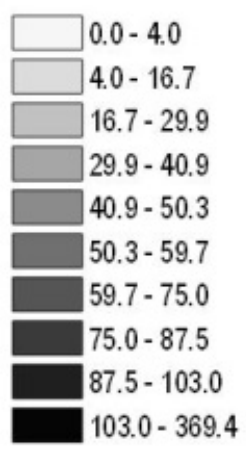

intgração Global (Rn)
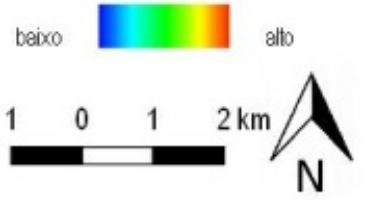

FONTE DE DADOS:

Estados, Brasil; Malha Municipal Dig. - 2013,

IBGE

Sist Referência: SIRGAS $200023 \mathrm{~S}$

Sist Projeção: UTM

Set/2016

Mapa 4: Integração X Demografia de São Carlos - SP

Fonte: Schroeder (2015) e IBGE (2010).

Elaborado pelos autores com base nos dados disponíveis no IBGE.

No que diz respeito à integração (Mapas 2 e 4), o núcleo integrador da cidade de São Carlos corresponde à área mais central que, são as áreas que vêm apresentando nas últimas décadas uma queda na sua densidade. Vale destacar, neste sentido, que a população que antes residia nestas áreas mais integradas, têm dado preferência por residir em empreendimentos fechados nas franjas urbanas, que é o modelo que têm induzido à uma expansão sob baixa densidade e segregada do ponto de vista da malha viária no setor norte e noroeste, ao permanecer em áreas integradas do ponto de vista configuracional, como já indicado anteriormente.

\section{CONSIDERAÇÕES FINAIS}

Com o crescimento populacional provocado pelo deslocamento das atividades produtivas do setor industrial, a cidade de São Carlos apresentou uma expansão física do seu território que, associado às novas estratégias do mercado imobiliário, como a produção de habitação de Interesse Social e condominios residenciais exclusivos, as áreas de expansão urbana não escapou dos conflitos territoriais da realidade brasileira, e a expansão física dessa nova dinâmica urbana tem se baseado na expansão horizontal do 
território urbanizado. Nesse sentido, em paralelo as questões interurbanas, mas não menos importante, o novo modelo de ocupação urbana tem transformado essas cidades no processo de assentamento decorrente do movimento migratório. Portanto, é possivel afirmar que a cidade estudada teve um papel importante na reestruturação econômica do país a partir da reorganização do setor industrial das cidades do interior paulista, produzindo, simultaneamente, modificações de cunho urbanístico especialmente em seus aspectos segregacionista que, anteriormente era evidente apenas nos grandes centros urbanos mas que atualmente também tem caracterizado as cidades de menor porte

Cabe ressaltar que a segregação socioespacial em São Carlos ocorre a partir da expansão do mercado imobiliário que têm construído empreendimentos condominiais destinados para a população de média e alta renda, com baixa densidade em áreas segregadas do ponto de vista configuracional. Isso demonstra que essas classes econômicas têm dado preferência pelo isolamento nesses empreendimentos do que pela integração com a cidade. Em contrapartida, o mercado fundiário e imobiliário tem reforçado a segregação socioespacial do setor sul e sudoeste a partir da implantação de conjuntos destinados à população de baixa renda, também em áreas segregada do ponto de vista configuracional mas que, diferentemente da malha segregada do eixo norte e noroeste, está associada à alta densidade e não apresenta proximidade física do eixo de alta escolha.

A partir de uma leitura sintática, isso demonstra que a população de alta renda, apesar de morar em áreas segregada do ponto de vista configuracional como a população de baixa renda, são privilegiadas pela proximidade com o eixo de alta escolha que a conecta com as áreas que contêm maior oferta de comércio, serviço e oportunidades de emprego.

Assim, a produção imobiliária em São Carlos tem consolidado uma divisão de ocupação do território urbano por renda, mesmo quando os extremos ocupam áreas com a malha viária segregada, na qual se constitui um modelo habitacional de alto padrão, sobretudo na porção norte e noroeste da cidade, e predominância da população com menor poder aquisitivo, sobretudo na porção sul e sudoeste. Esse aspecto evidencia que a segregação baseada na dicotomia centro rico e periferia pobre já não é capaz de traduzir a segregação socioespacial nas cidades brasileiras, mesmo quando as áreas periféricas são distintas do ponto de vista socioeconômico mas semelhantes do ponto de vista configuracional.

O modo desigual da produção do espaço urbano ocorre pela permanência da concentração da população de menor renda em áreas periféricas, mas também pela proliferação de empreendimentos habitacionais confinados destinados pela população de maior renda que também se insere nas áreas periféricas. Assim, percebe-se pelos resultados encontrados que, independente do porte da cidade, os atores responsáveis pela produção do espaço urbano permanecem construindo cidades cada vez mais segregadas, mesmo que nesse estudo a espacialização desse fenômeno tenha encontrado mais diferenças do que semelhanças. Contudo, se faz necessário uma qualificação dos órgãos públicos brasileiros,especializados em planejamento urbano/regional e que utilizem, de fato, ferramentas para análises territoriais. A elaboração de mapas sintáticos aliados a correlação de dados sociais permitem transparecer os pontos positivos que merecem ampliação e os aspectos negaticos que carecem de maior atenção e, assim, proporcional maior auxílio ao desenvolvimento territorial.

A Sintaxe Espacial permitiu analisar na cidade de São Carlos que diferentes configurações interferem sobre a vida social. Em outras palavras, a variável configuracional possibilitou uma discussão teórica e metodológica sobre a configuração urbana e a segregação socioespacial, sendo esta correlação aspectos importantes mas que ainda carecem de estudos que abordam um melhor entendimentos das características do espaços considerando sua lógica social. Assim, o estudo a partir dos mapas axiais contribuiu para um melhor entendimento da segregação socioespacial ao quantificar como a malha viária da cidade influencia no facilidade de acesso do espaço urbano qualificado.

\section{REFERÊNCIAS BIBLIOGRÁFICAS}

ACSELRAD, H. (2007). Vigiar e Unir: a Agenda da Sustentabilidade Urbana? Revista VeraCidade. Ano 2, $\mathrm{n}^{\circ}$ 2, 1-11.

BELLET SANFELIU, C.; LLOP TORNÉ, J. M. (2004). Miradas a otrosespacios urbanos: lasciudades intermedias. Scripta Nova, Revista electrónica de Geografia y CienciasSociales. Universidad de Barcelona, España, 165. Disponível em: <http://www.ub.es/geocrit/sn/sn-165.htm>. (Consulta em:10/12/2016). 
BONDUKI, N.; ROLNIK, R. (1982). Periferia da Grande São Paulo: reprodução do espaço como expediente de reprodução da força de trabalho. Em MARICATO, E. (comps.) A produção capitalista da casa (e da cidade) do Brasil industrial. São Paulo: Alfa-ômega.

CALDEIRA, T. P.R. (2000). Cidade de muros: crime, segregação e cidadania em São Paulo. São Paulo: Edusp.

CANO, W. (2008). Desconcentração Produtiva Regional do Brasil 1970-2005. São Paulo: Editora UNESP.

CARLOS, A. F. A. (2011) O espaço como condição para reprodução. A condição espacial. São Paulo: Contexto.

CARVALHO, E. (2003). Exclusão social e crescimento das cidades médias brasileiras. Scripta Nova Revista electrónica de geografía y cienciassociales. Universidad de Barcelona, VII 146. Disponível em: <http://www.ub.es/geocrit/sn/sn-146(128).htm>. (Consulta em:10/03/2016).

CASTELLS, M. (1983) A Questão Urbana. Rio de Janeiro: Paz e Terra.

CORRÊA, R. L. (1989) O Espaço Urbano. São Paulo: Ática.

. (2013) Segregação residencial: classes sociais e espaço urbano. In: VASCOBCELOS, P. A.; CÔRREA, R. L.; PINTAUDI, S. M. (Comps.). A cidade contemporânea: segregação espacial (39-59). São Paulo: Contexto.

GÓMEZ S., CÉSAR J. (2011). El fragmento urbano residencial enlaconstrucción de lametrópoli barcelonesa (1976-2006). Tese de Doutorado. Escuela Técnica Superior de Arquitectura de Barcelona - Universidad Politécnica de Cataluña, Barcelona - Espanha.

HILLIER, B.; HANSON, J. (1984) The social logic of space. Cambridge: Cambridge Press.

HOLANDA, F. (2001). Sintaxe espacial: introdução por meio de material empírico. Apostila de aulas da disciplina Teoria do Conhecimento e dos Espaços Construídos, adotada na disciplina Espaço e Organização Social do PPG-FAU, 7, Universidade de Brasília.

--- (2002): O espaço de exceção. Brasília: EdUnB.

IBGE - Instituto Brasileiro de Geografia e Estatística (2016). Santa Catarina, São Bento do Sul. Disponível em: <http://www.cidades.ibge.gov.br/xtras/perfil.php?lang=\&codmun=4215802>. Acesso em: 06 set. 2016.

IBGE - Instituto Brasileiro de Geografia e Estatística. (2016). Disponível em: $<$ <ttp://www.cidades.ibge.gov.br/xtras/perfil.php?lang=\&codmun=354890>. Acesso em: 06 set. 2016.

KOWARICK, L. A (1979). Espoliação Urbana. Rio de Janeiro, Paz e Terra.

LENCIONI, S. (2003). Cisão territorial da indústria e integração regional do estado de São Paulo. Em GALVÃO, C., GONÇALVES, M.F., BRANDÃO, A. (Org.). Regiões e cidades, cidades nas regiões: o desafio urbano regional (465-475). São Paulo: UNESP, ANPUR.

LOJKINE, J. (1997) O estado capitalista e a questão urbana. São Paulo: Martins Fontes.

LUCO, C. A.; VIGNOLI, J.R. (2003). Segregación residencial en áreas metropolitanas de América Latina: magnitud, características, evolución e implicaciones de política, 47. Santiago del Chile: CEPAL.

MARICATO, E. (2006). O Ministério das Cidades e a política nacional de desenvolvimento urbano. Políticas sociais - acompanhamento e análise n12, (211-220) Brasília: IPEA.

MARQUES, E. (2014). A estrutura social e segregação em São Paulo: transformações na década de 2000. Em Revista Ciências Sociais, 57(3), 675-710.

MEDEIROS, V. A. S. (2006). UrbisBrasiliae ou sobre cidades do Brasil: inserindo assentamentos urbanos do país em investigações configuracionais comparativas. Tese (Doutorado) Faculdade de Arquitetura e Urbanismo, Universidade de Brasília: Brasília. 
MELAZZO, E. (1993). Mercado Imobiliário, expansão territorial e transformações intraurbanas: o caso de Presidente Prudente-SP/1975-1990. Rio de Janeiro: Universidade Federal do Rio de Janeiro, Dissertação (Mestrado em Economia).

NETTO, V. M. (2013) O que a sintaxe espacial não é? Arquitextos, São Paulo, ano 14, n. 161.04, Vitruvius, <http://www.vitruvius.com.br/revistas/read/arquitextos/14.161/4916>. Consulta: 10/04/2017)

OLIVEIRA, I. C. E. (2001). Estatuto da cidade para compreender, 64. Rio de Janeiro: IBAM/DUMA.

PEREIRA, R. H.M., BARROS, GONÇALVES A.P., HOLANDA, F.R.B., MEDEIROS, V.A.S. (2011) O uso da Sintaxe Espacial no desempenho do transporte urbano: limites e potencialidades. Texto para Discussão 1630. IPEA: Brasília.

RIBEIRO, L. C. Q. (1997) Dos cortiços aos condomínios fechados: as formas de produção da moradia na cidade do Rio de Janeiro. Rio de Janeiro: Civilização Brasileira.

ROLNIK, R. (2008). A lógica da desordem. In: Lê Monde Diplomatique Brasil. Ano 2 n 13, ago.3008, pp. 101. São Paulo.

SANTOS. A. M. (2010) Política Urbana: a importância de focalizar as cidades médias. Revista de Direito da Cidade, Rio de Janeiro, v.05, n. 02, 153- 177.

. (2011). Cidades médias: novas fronteiras de oportunidades. Em ANGELA M.S., PENALVA S., GLAUCIO J.M., SANT`ANNA. M.J.G. (Org.). Rio de Janeiro: Um território em mutação. (47-72). Rio de Janeiro: Gramma.

SIQUEIRA. B. V. (2015). Produção de periferias urbanas em ciudades médias paulistas: o caso de São Carlos e São José do Rio Preto. Dissertação de Mestrado. São Carlos: UFSCAR.

SOBARZO, O. (1999). A segregação sócio-espacial em Presidente Prudente: análise dos condomínios horizontais. Dissertação de Mestrado. Presidente Prudente: UNESP.

--- (2006): A produção do espaço público em Presidente Prudente: reflexões na perspectiva dos loteamentos fechados. Em SPÓSITO, E.S., SPÓSITO BELTRÃO, M.E., SOBARZO, O. (orgs). Cidades médias: produção do espaço urbano e regional, (199-214). São Paulo: Expressão popular.

SPOSITO, M. E. B. (2007). Reestruturação urbana e segregação socioespacial no interior paulista Em Scripta Nova, Revista electrónica de geografía y cienciassociales, XI 245(11). Universidad de Barcelona, Barcelona,

--- (2012): Capitalismo e Urbanização. 16ª ed. São Paulo: Contexto.

--- (2013): A produção do espaço urbano: escalas, diferenças e desigualdades socioespaciais. Em CARLOS, A. F. A., SOUZA, M. L., SPOSITO, M. E. B. (Orgs.). A produção do espaço urbano: agentes e processos, escalas e desafios, (123-145). São Paulo: Contexto.

VASCONELOS, P. A. (2013) Contribuição para o debate sobre processos e formas socioespaciais nas cidades. Em VASCONCELOS, P. A.; CORRÊA, R. L.; PINTAUDI, S. M. (Orgs.). A Cidade Contemporânea: Segregação Espacial, (17-37). São Paulo: Contexto.

VIEIRA, A. B.; MELAZZO, E. Introdução ao conceito de segregação sócio espacial (2003) Revista Formação (Online), V. 1, $\mathrm{n}^{\circ}$ 10, Disponível em: < http:// revista.fct. unesp.br/index.php/formacao/article/view/1118>. Consulta: 05/01/2017.

VILLAÇA, F. (2001) O espaço intra-urbano no Brasil. São Paulo: Studio Nobel, FAPESP, Lincoln Instituteof Land Police.

. (2011). São Paulo: segregação urbana e desigualdade. Estudos Avançados, v. 25, n. 71, 37-58. 